\title{
Entanglement of zircon alteration events revealed at the nanometric scale.
}

\author{
ANNE-MAGALI SEYDOUX-GUILLAUME ${ }^{1}$, EMILIE \\ JANOTS $^{2}$, STÉPHANIE REYNAUD ${ }^{3}$ AND MARION \\ GROSJEAN $^{4}$ \\ ${ }^{1}$ LGL-TPE, UMR CNRS 5276 (CNRS, ENS, Université Lyon1, \\ UJM) \\ ${ }^{2}$ ISTerre-UGA \\ ${ }^{3} \mathrm{LabHC}$ \\ ${ }^{4}$ ISTerre
}

Presenting Author: anne.magali.seydoux@univ-st-etienne.fr

Recent advances in characterization techniques, such as in particular spherical aberration corrected- Scanning Transmission Electron Microscopy (Cs-STEM), allow to probe matter down to the nanometric scale. Minerals are the memory of rocks. They tell us stories on the nature, intensity or duration of geological processes, preserving traces that are often hidden and only revealed at the nanometric scale. In this study, we've used the TEM to explain both textural and isotopic complexities of zircon crystals from the Lauzière granite (External Crystalline Massifs, Western Alps). Granite microstructures and mineral parageneses indicate several alteration events that could occur during different tectonometamorphic events of the Variscan and Alpine orogenies. The ages and the links between fluid circulation and deformation events remain however misunderstood. To provide some answers, zircon crystals found in these granites have been studied. At the micrometric scale (SEM and CL) their structural and chemical characterization revealed complex structures: homogeneous cores (1) with intense CL signal, sometimes replaced by very porous cores (2) rich in thorium silicate (thorite) inclusions, and oscillatory rims (3) with a dark CL signal. $\mathrm{U}-\mathrm{Pb}$ in situ dating reveals that only homogeneous cores give magmatic ages around $340 \mathrm{Ma}$; the other domains give discordant dates that cannot be interpreted with these data alone. The TEM analysis of FIB sections prepared in these various domains provides clues to explain these date disturbances. In particular, TEM reveals cores (2) filled with nanopores (20-50 $\mathrm{nm}$ ), and also dislocations, which seems to progress to the detriment of perfectly crystallized cores (1). These nanocharacterizations also point out oscillatory borders, with alternation of thin bands $(50-200 \mathrm{~nm})$ enriched in uranium and containing high density of irradiation damage, and wider bands $(0.5-2 \mu \mathrm{m})$ free of irradiation defects and depleted in $\mathrm{U}$; these features may explain the discordant dates. 